\title{
Early Prognosis Effect of Cellular Immune Paralysis on Brain Complications of Extracorporeal Membrane Oxygenation Children with Severe Sepsis
}

\author{
Yan Xing Dongliang Cheng Changsong Shi Zhiqing Shen \\ Pediatric Intensive Care Unit (PICU) of People's hospital of Henan Province, People's Hospital of Zhengzhou \\ University, Zhengzhou, China
}

\section{Keywords}

Pediatric pneumonia with severe sepsis - Extracorporeal membrane oxygenation - Brain complications $\cdot$ CD11 $\mathrm{b}^{+}$ cells · Immunological paralysis · Endothelial injury

\begin{abstract}
Objective: The aim of the study was to explore the relationship between criticality, brain complications, and immune mechanisms in extracorporeal membrane oxygenation (ECMO) children with pneumonia and severe sepsis. Methods: Patients with simple pneumonia (group I), ECMO patients with pneumonia and severe sepsis accompanied by brain complications (group II), and those without brain complication (group III) admitted to our pediatric intensive care unit were selected to be investigated. The relationship among the peripheral blood subgroups of immune cells, immune factors, adaptive immune responses, endothelial factors, and criticality and brain complications was then studied. Results: Severe paralysis of normal immunity, excess abnormal immunity, and endothelial injury were consistent with the increase in the absolute value of base excess, lactic acid (Lac) content, and average hospitalization days and brain complications involved in group II (vs. group I). The ratio of $\mathrm{CD}^{+} 3^{+}$macrophage and $\mathrm{CD}^{+} 3^{+}$neutrophil subpopulation increased $(p<0.05)$; the expression levels of elastase ${ }^{+}$ neutrophil denatured subgroup ( $p<0.05$ ), the ratio of CCR $2^{\text {high }} C X 3 C R 1^{\text {low }} / C C R 2^{\text {low }} C X 3 C R 1^{\text {high }}$ of macrophages and
\end{abstract}

karger@karger.com

(c) 2021 S. Karger AG, Basel

www.karger.com/nim

Karger! neutrophils $(p<0.0001)$, high-mobility group box 1 (HMGB1), YTHDF1, interleukin-17 protein and mRNA, and RAGE gene decreased to some extent $(p<0.05)$; the expression levels of Th1 cells chemokine CXCL9 protein and mRNA and STIE2 protein increased to some extent $(p<0.05)$; the adaptive immune response of $\mathrm{CD}^{+} \mathrm{CTL}$ stimulated by lipopolysaccharide (LPS) was slightly enhanced $(p<0.05)$ in group III(vs. group II), which was consistent with the improvement of criticality, average hospitalization days, and the absence of brain complications in group III (vs. group II). Conclusion: ECMO support with brain complication was related to the upregulation of HMGB1 and YTHDF1 protein; the decreased number of $\mathrm{CD}^{+} 3^{+}$macrophages and neutrophils; the increased denatured neutrophil subgroup, especially the upregulated ratio of $C C R 2^{\text {high }} C X 3 C R 1^{\text {low }} / C C R 2^{\text {low }} C X 3 C R 1^{\text {high }}$ of macrophages and neutrophils; the imbalance of Th17/Th1, LPS-specific $\mathrm{CD}^{+} \mathrm{CTL}$ adaptive immune response paralysis; and the reduced endothelial STIE2 protein expression level which caused clinical deterioration and prolonged average hospitalization days.

(c) 2021 S. Karger AG, Basel

\section{Introduction}

Severe pneumonia is one of the most common causes of pediatric severe sepsis. There are 156 million children with pneumonia in the world every year. The incidence 
of severe pneumonia among children younger than 5 years is from 10 to $15 \%$ [1]. Severe pneumonia causes $21 \%$ of mortality in children $<5$ years and accounts for the first place in critical children illness [2], and the incidence of pneumonia complicated by severe sepsis is 22 in 100,000 cases, and the mortality rate is from 9 to $22 \%$ [3] in which the cases requiring extracorporeal membrane oxygenation (ECMO) support account for 1/25-1/100 [4].

Pneumonia and severe sepsis are related not only to the increasing drug resistance of pathogens such as bacteria, viruses, and protoplasts but also to the imbalance of the inflammation and anti-inflammatory system and the disorder of immune function. When sepsis occurs, a large number of immune cells become apoptotic and phagocytes turn dysfunctional, which causes excessive inflammatory reaction, and the body attains an immune paralysis state. After the sepsis is improved, the patient is more susceptible to pathogenic bacterial infection than normal people, increasing the death risk [5]. Therefore, the research on sepsis immunotherapy has attracted considerable attention in recent years [6]. So far, clinical research found that pediatric pneumonia and severe sepsis with ECMO support had decreased $T$ cells, and brain-targeting adaptive immunity, aggravating brain damage [7], but the whole inherent and adaptive immune mechanisms are still unclear.

In order to provide clinical individual diagnosis and treatment clues for pediatric pneumonia and severe sepsis supported by ECMO, the biochemical parameters, critical degree, and whether accompanied by brain complication or not were analyzed. The changes in peripheral blood neutrophils, macrophages, and T-cell phenotypes, as well as the damage-related molecules and their receptors, chemokines, cytokines, and adaptive immune responses and endothelial-related molecules, and their relationship with the brain complications of pediatric pneumonia and severe sepsis supported by ECMO were also analyzed in the present research.

\section{Research Objects and Methods}

\section{Human Subjects}

Five patients with pediatric simple pneumonia, 7 ECMO patients with severe pneumonia and sepsis with the subsequent brain complications, and 6 ECMO patients with severe pneumonia and sepsis without subsequent brain complications who were admitted to the pediatric intensive care unit ward of People's Hospital of Henan Provincial from February 1, 2017 to October 30, 2019 were ultimately examined in the studies.

\section{Diagnostic Criteria}

Diagnostic Criteria of Pneumonia with Sepsis and

\section{ECMO Indication}

Referring to the 2007 IDSA/ATS diagnostic criteria for pneumonia [8], diagnosis should be according to the following criteria: rapid breathing, cough, and lung rales, excluding cardiac factors, foreign bodies, asthma, infections other than bacterial infections, congenital immunodeficiency, lung dysplasia, and haemosiderosis, etc. Severe sepsis in children in the present research includes symptoms and signs of inflammation and infection, accompanied by fever or hypothermia, in which the rectal temperature can be $>38.5^{\circ} \mathrm{C}$ or $<35^{\circ} \mathrm{C}$; tachycardia, which can lack low body temperature; change of consciousness; and reliance on vasopressors or inotropes, which is also called catecholamine-dependent sepsis, which must also have one of the following indexes including an arterial oxygen pressure/inspiratory oxygen concentration $\left(\mathrm{PaO}_{2} / \mathrm{FiO}_{2}\right)<200 \mathrm{~mm} \mathrm{Hg}$, lactic acid (Lac) $>2 \mathrm{mmol} / \mathrm{L}$, urine volume after adequate fluid resuscitation $<0.5 \mathrm{~mL}$ $\mathrm{kg}^{-1} \mathrm{~h}^{-1}$, serum creatinine $>2.0 \mathrm{mg} / \mathrm{dL}(176.8 \mu \mathrm{mol} / \mathrm{L})$, bilirubin $>2.0 \mathrm{mg} / \mathrm{dL}(34.2 \mu \mathrm{mol} / \mathrm{L})$, PLT less than $20 \times$ $10^{12} / \mathrm{L}$, and international normalized ratio $>1.5$ [9]. ECMO support indications include severe respiratory failure, persistent $\mathrm{PaO}_{2} / \mathrm{FiO}_{2}<60-80 \mathrm{~mm} \mathrm{Hg}$ or oxygenation index (OI) $>40$, no response to conventional mechanical ventilation and other respiratory support treatments (high-frequency nitric oxide inhalation, prone position ventilation), high mechanical ventilation pressure (conventional ventilation average airway pressure $>20$ $25 \mathrm{~cm} \mathrm{H} 2 \mathrm{O}$ and high-frequency ventilation $>30 \mathrm{~cm} \mathrm{H}_{2} \mathrm{O}$ ) or pressure injury; and respiratory failure with persistent hypercapnia $(\mathrm{pH}$ value $<7.1$ ).

\section{Inclusion and Exclusion Criteria}

Firstly, the ECMO children stayed in the pediatric intensive care unit of Henan people's hospital for $>24 \mathrm{~h}$ and with pneumonia and/without severe sepsis from February 1, 2017 to October 30, 2019. Informed consent was signed and passed the review of the Hospital Ethics Committee.

Secondly, within 28 days of admission, brain complications, if any, after ECMO support, including various diffuse brain dysfunctions such as attention change, memory change, orientation change, writing failure, increased muscle tone, paralysis, coma, ischemic stroke, brain ischemia, brain abscess, and epilepsy [10] were followed up. Finally, the following cases were excluded, such as primary brain disease, congenital metabolic disease, hematological disease, nephritis nephropathy, rheuma- 
toid connective tissue disease, lung cancer, tuberculosis, AIDS, patients who underwent tumor radiotherapy and chemotherapy, mental illness, trauma, poisoning, and children who died within $24 \mathrm{~h}$ of admission.

\section{Grouping}

Based on clinical data and laboratory tests collected from $24 \mathrm{~h}$ to 28 days of admission, patients were divided into the simple pneumonia group (group I, 5 cases), pneumonia and severe sepsis with ECMO support accompanied by brain complications (group II, 7 cases), pneumonia and severe sepsis with ECMO support without brain complications (group III, 6 cases). On the 7th day of conventional treatment, the following indicators of children were determined: gender, age, WBC count, $\mathrm{Hb}$, PLT count, C-reactive protein (CRP), procalcitonin (PCT), blood gas analysis, Lac, base excess (BE), OI, urine volume, liver and kidney function, myocardial enzyme, and coagulation function. Also, criticality was measured after 7 days of treatment, a score $>80$ was considered noncritical, 80 to 71 critical, and less than 70 extremely critical [11]. Peripheral blood was taken for CRP, PCT, Lac, $\mathrm{BE}, \mathrm{PaO}_{2} / \mathrm{FiO}_{2}$, and flow cytometry determination; plasma for ELISA; and peripheral blood leukocytes for RTPCR, ELISpot, and Western blot.

\section{Immunological and Molecular Biological \\ Determination}

The number of $\mathrm{CD}^{+} 3^{+}$neutrophils and M1 macrophages; the ratio of $\mathrm{CCR} 22^{\text {high }} \mathrm{CX} 3 \mathrm{CR} 1^{\text {low }} / \mathrm{CCR} 2^{\text {low }} \mathrm{CX}$ $3 \mathrm{CR} 1^{\text {high }}$ of macrophages and neutrophils, $\mathrm{CD} 4^{+}$, and $\mathrm{CD}^{+} \mathrm{T}$ lymphocytes; and expression amount changes of elastase related to neutrophil extracellular traps (NET) in peripheral blood were determined. $\mathrm{CD} 8^{+} \mathrm{CTL}$ adaptive immune response stimulated by lipopolysaccharide (LPS), expression of plasma protein of pro-inflammatory and anti-inflammatory factors and vascular endothelial growth factor (VEGF), and the mRNA level of high-mobility group box 1 (HMGB1) (high mobility group box-1) and its receptors RAGE, TLR9, and YTHDF1; cytokines tumor necrosis factor- $\alpha(T N F-\alpha)$, interleukin $(I L)-27$, and IL-17; and chemokines CXCL9 and CXCL10 in peripheral blood leukocytes; and plasma proteins HMGB1, CXCL9, and IL-17; and endothelial-related molecules Ang2/Ang1 and sTIE2 and brain injury protein NSE (neuron-specific enolase); and HMGB1 and YTHDF1 proteins in peripheral blood leukocytes were also determined. The relationship between the above clinical indicators of each group and Lac, BE, OI, average hospital stay, and brain complications was investigated in the present research.

Immune Paralysis of Brain Injury with Sepsis-ECMO
Flow Cytometry and ELISA Analysis

$200 \mu \mathrm{L}$ of peripheral anticoagulation blood was mixed with $1 \mathrm{~mL}$ of hemolysin (BD, America) for $5 \mathrm{~min}$ and then $5 \mathrm{~mL}$ of $1 \times$ PBS was added to stop hemolysis. The cells were collected after centrifugation at 1,200 rpm for $5 \mathrm{~min}$ and then $2 \mathrm{~mL}$ of $1 \times$ PBS was added washing, and the cells were collected again. Then, $20 \mu \mathrm{L}$ of cell suspension was mixed with $2 \mu \mathrm{L}$ APC-mouse anti-human CD3 antibody (1:10, cell signaling), $2 \mu \mathrm{L}$ Pcy7-mouse anti-human CD11b antibody (1:10, Abcam), $2 \mu$ LITC-rabbit anti-human ly6g antibody (1:10, Abcam), and $2 \mu \mathrm{L}$ PE-rabbit anti-human CD63antibody (1:10, cell signaling), or with $2 \mu \mathrm{L}$ Pcy7-mouse antihuman CD11b antibody (1:10, Abcam), $2 \mu \mathrm{L}$ FITC-rabbit anti-human ly6g antibody (1:10, Abcam), $2 \mu \mathrm{L}$ APC-mouse anti-human CCR2antibody (1:10, cell signaling), and $2 \mu \mathrm{L}$ PE-rabbit anti-human CX3CR1antibody (1:10, cell signaling) and incubated at room temperature for $30 \mathrm{~min}$. Then, the mixture was diluted with $2 \mathrm{~mL}$ of $1 \times$ PBS and centrifuged at 1,200 rpm for $5 \mathrm{~min}$ to collect the cells. The above operation was repeated once more, and then the cells were resuspended with $2 \mathrm{~mL}$ of $1 \times \mathrm{PBS}$ for flow cytometry analysis to detect peripheral blood $\mathrm{CD}^{-} / \mathrm{CD} 11 \mathrm{~b}^{+} / \mathrm{ly} \mathrm{g}^{+} /$ $\mathrm{CD}^{+} 3^{+}$(neutrophil $\mathrm{CD}^{+} 3^{+}$subtype), $\mathrm{CD} 3^{-} / \mathrm{CD} 11 \mathrm{~b}^{+} / \mathrm{ly} 6 \mathrm{~g}^{-} /$ $\mathrm{CD}^{+} 3^{+}$(macrophage $\mathrm{CD}^{+} 3^{+}$subtype), $\mathrm{CD} 11 \mathrm{~b}^{+} / \mathrm{ly} 6 \mathrm{~g}^{+/-} /$ CCR2 $2^{\text {high }}$ CX3CR1 $1^{\text {low }}$ subtype, and $\mathrm{CD} 11 \mathrm{~b}^{+} / \mathrm{ly} 6 \mathrm{~g}^{+/-} /$ CCR $2^{\text {low }}$ CX3CR $1^{\text {high }}$ subtypes.

The preparation process of cell suspension was the same as mentioned above. Twenty microlitres of cell suspension was mixed with $100 \mu \mathrm{L}$ of $1 \%$ paraformaldehyde to fix for $8 \mathrm{~min}$ and then $2 \mathrm{~mL}$ of $1 \times$ PBS was added and centrifuged at 1,200 rpm for $5 \mathrm{~min}$. The cells were collected and mixed with $100 \mu \mathrm{L}$ of $0.1 \%$ saponin for $8 \mathrm{~min}$ to prepare a permeable membrane and then $2 \mathrm{~mL}$ of $1 \times$ PBS was added for washing, and then the cells were centrifuged at 1,200 rpm for $5 \mathrm{~min}$, and the cells were collected and washed by $1 \times$ PBS again. Then, the cells were mixed with $8 \mu \mathrm{L}$ of FITC-rabbit anti-human elastase antibody (1:10, cell signaling) for $30 \mathrm{~min}$ at room temperature, and $2 \mathrm{~mL}$ of $1 \times$ PBS was added for washing and centrifuged at 1,200 rpm for $5 \mathrm{~min}$, and the cells were washed by PBS again. The cells collected were resuspensed with $2 \mathrm{~mL}$ of PBS for flow cytometry analysis. The cells were treated with isotype FITC-labelled (rabbit antihuman, 1:20, ebioscience) and PE-labelled (mouse antihuman, 1:20, Ebioscience) control antibodies without the above primary antibody as negative control.

10,000 cells were counted for each group on flow cytometry. Kaluza1.3 software was used for analysis and statistics of various cell proportions. Human $\mathrm{CD} 4^{+}$and $\mathrm{CD} 8^{+}$ $\mathrm{T}$ lymphocytes were detected using a T-cell subset detec-

Neuroimmunomodulation 2021;28:233-247 235 
Table 1. Clinical data grouping

\begin{tabular}{lllll}
\hline & Group I & Group II & Group III & $\chi^{2}$ or $t$ value \\
\hline All cases, $n$ & 5 & 7 & 6 & \\
Male (case) & 3 & 3 & 4 & $0.40,0.50,1.67$ \\
Female (case) & 2 & 4 & 2 & $0.67,0.29,0.55$ \\
Age, months & $7.16 \pm 2.81$ & $7.74 \pm 3.20$ & $7.27 \pm 3.06$ & 0 \\
\hline
\end{tabular}

Group I: simple pneumonia group; group II: pneumonia and severe sepsis with ECMO support with brain complication group; group III: pneumonia and severe sepsis with ECMO support without brain complication group. ECMO, extracorporeal membrane oxygenation.

tion kit (Beijing Keruimei Technology Co., Ltd.) on flow cytometry (Beckman Coulter, CA, USA). Human TNF- $\alpha$, IL-10, VEGF, HMGB1, CXCL9, Ang1, Ang2, sTIE2, and NSE were detected respectively by ELISA kits (BioRad Life Medicine Products [Shanghai] Co., Ltd.), and the procedure was performed according to the instructions.

\section{RT-PCR}

The collected peripheral blood leukocytes were stored in TRIzol solution at $-80^{\circ} \mathrm{C}$. Total RNA was extracted using a human blood RNA extraction kit (Qiagen RNeasy, Qiagen Biochemical Company, China). Primers were designed using PubMed gene bank and primer bank. The total cDNA was obtained using a RevertAid RT Reverse Transcription Kit (Thermo, Waltham, MA, USA). The PCR was carried out using an SYBR FAST qPCR MasterMix kit (Sigma, St. Louis, MO, USA), and the CT value was detected using a BioRAD fluorescence quantitative PCR instrument. The $2^{-\Delta \Delta}$ CT method was used to calculate the relative $\mathrm{CT}$ value after comparing with glyceraldehyde-3-phosphate dehydrogenase.

\section{ELISpot}

The procedure was carried out as per the article [12].

\section{Western Blot}

The cells in each group were lysed in $1 \times$ RIPA buffer. After SDS-PAGE separation, the protein was transferred onto a PVDF membrane and incubated with HMGB1 and YTHDF1 primary antibody (1:500) (Santa Cruz, CA, USA). The optical density was measured to determine the relative protein expression, with glyceraldehyde-3-phosphate dehydrogenase as the endogenous reference (1:1,000, Santa Cruz, CA, USA).

\section{Statistical Analysis}

Graphpad Prism 5.0 software was used for statistical analysis. The correlation between clinical indexes and critical illness scores was analyzed by linear regression analysis. The measurement data were expressed as $\mathrm{x} \pm \mathrm{s}$, and the normality test and the homogeneity test of variance were performed for each group. The data conformed to the normal distribution and had homogeneity of variance, so the $t$ test was used for comparison between the 2 groups. The count data were statistically described using frequency, and the 2 groups were compared using the $\chi^{2}$ test. A $p$ value $<0.05$ was considered to be statistically significant.

\section{Results}

\section{Clinical Data Grouping}

Five patients were with simple pneumonia, 3 male and 2 female patients, aged from 2.5 to 11.5 months. Seven ECMO patients were with pneumonia and severe sepsis accompanied by brain complications, 3 male and 4 female patients, aged from 2.3 to 15 months. Six ECMO patients were with pneumonia and severe sepsis without brain complications, 4 male and 2 female patients, aged from 2.0 to 13 months. There was no significant difference in gender and age between the groups (Table 1).

\section{Regression Analysis of the Correlation between}

Clinical Indicators and Criticality Scores on the 7th

\section{Day of Three Groups}

PCT concentration was higher than $0.25 \mathrm{ng} / \mathrm{mL}$ for $71 \%$ of patients on the first day of admission. All patients in the present study responded well to antibiotic therapy. On day 5 after receiving antibiotic therapy, the mean CRP and/or PCT concentrations of children decreased significantly. Therefore, it suggested that pneumonia in children was caused by bacterial infection.

Compared with group I, the latter 2 groups had significantly higher CRP, PCT, BE absolute value, Lac, bilirubin, serum creatinine, activated partial thromboplastin time, 
Table 2. Comparison of clinical data analysis among 3 groups

\begin{tabular}{|c|c|c|c|c|c|}
\hline & Group I & Group II & Group III & $t$ value ( $p$ value) & $R^{2}$ value \\
\hline Critical score & $85.67 \pm 3.60$ & $55.93 \pm 11.14$ & $68.33 \pm 5.95$ & $5.67^{* * *}, 5.97^{* * *}, 3.09^{\#}$ & \\
\hline WBC, $1 \times 10^{9} / \mathrm{L}$ & $11.86 \pm 4.34$ & $14.61 \pm 6.99$ & $12.92 \pm 5.18$ & $0.75,1.60,2.03$ & 0.7342 \\
\hline $\mathrm{Hb}, \mathrm{g} / \mathrm{dL}$ & $110 \pm 33$ & $95 \pm 38$ & $100 \pm 35$ & $1.11,1.05,0.53$ & 0.9643 \\
\hline $\mathrm{PLT}, \times 10^{9} / \mathrm{L}$ & $150 \pm 58$ & $25 \pm 19$ & $80 \pm 45$ & $7.16^{* * *}, 16.57^{* * * *}, 6.95^{\# \# \#}$ & 0.9952 \\
\hline $\mathrm{CRP}, \mathrm{mg} / \mathrm{L}$ & $5.11 \pm 2.31$ & $50.65 \pm 21.57$ & $45.22 \pm 18.74$ & $13.51^{* * * *}, 14.68^{* * * *}, 1.1$ & 0.8376 \\
\hline $\mathrm{BE}, \mathrm{mmol} / \mathrm{L}$ & $-(2.5 \pm 1.1)$ & $-(10.56 \pm 3.5)$ & $-(4.3 \pm 2.3)$ & $9.74^{* * * *}, 12.32^{* * * *}, 7.88^{\# \# \#}$ & $0.9989^{+}$ \\
\hline $\mathrm{Lac}, \mathrm{mmol} / \mathrm{L}$ & $0.8 \pm 0.3$ & $6.3 \pm 1.1$ & $2.5 \pm 0.7$ & $6.08^{* * *}, 7.38^{* * *}, 3.57^{\# \#}$ & $0.9985^{+}$ \\
\hline Urine volume, $\mathrm{mL} / \mathrm{kg} / \mathrm{h}$ & $3.5 \pm 1.4$ & $0.7 \pm 0.4$ & $1.5 \pm 0.9$ & $6.06^{* * *}, 9.72^{* * * *}, 2.19^{\#}$ & 0.9231 \\
\hline Blood pressure, $\mathrm{mm} \mathrm{Hg}$ & $71 \pm 27$ & $50 \pm 17$ & $55 \pm 22$ & $3.42^{* *}, 3.37^{* *}, 1.56$ & 0.6371 \\
\hline Bilirubin, mg/dL & $0.5 \pm 0.2$ & $2.4 \pm 1.0$ & $1.9 \pm 0.9$ & $8.43^{* * *}, 10.40^{* * * *}, 2.00$ & 0.9918 \\
\hline Serum creatinine, $\mathrm{mg} / \mathrm{dL}$ & $0.3 \pm 0.1$ & $2.3 \pm 1.0$ & $2.1 \pm 0.5$ & $11.38^{* * * *}, 10.95^{* * * *}, 1.01$ & 0.9967 \\
\hline INR & $0.8 \pm 0.2$ & $2.1 \pm 0.7$ & $2.2 \pm 0.5$ & $5.26^{* * *}, 12.38^{* * * *}, 2.15$ & 0.9530 \\
\hline Fib, g/L & $2.3 \pm 1.0$ & $1.2 \pm 0.5$ & $1.4 \pm 0.9$ & $3.38^{* *}, 11.74^{* * * *}, 1.93$ & 0.9973 \\
\hline D-dimer & $0.5 \pm 0.3$ & $3.7 \pm 1.0$ & $3.2 \pm 0.8$ & $11.58^{* * * *}, 12.04^{* * * *}, 2.00$ & 0.9113 \\
\hline Average length of hospital stay & $13 \pm 5$ & $35 \pm 11$ & $25 \pm 9$ & $8.72^{* * * *}, 11.46^{* * * *}, 8.89^{\# \# \# \#}$ & $0.9973^{+}$ \\
\hline
\end{tabular}

Group I: simple pneumonia group; group II: pneumonia and severe sepsis with ECMO support with brain complication group; group III: pneumonia and severe sepsis with ECMO support without brain complication group. PCT, procalcitonin; CRP, C-reactive protein; $\mathrm{BE}$, base excess; Lac, lactic acid; ECMO, extracorporeal membrane oxygenation; $\mathrm{PaO}_{2} / \mathrm{FiO}_{2}$, oxygen pressure/inspiratory oxygen concentration; PT, plasmaprothrombin time; APTT, activated partial thromboplastin time. ${ }^{* *} p<0.01 .{ }^{* * *} p<0.001$. ${ }^{* * * *} p<0.0001$ versus group I. ${ }^{\#} p<0.05$. ${ }^{\# \#} p<0.01$. ${ }^{\# \#} p<0.001$. ${ }^{\# \# \#} p<0.0001$ versus group II. ${ }^{+} p<0.05$, the regression analysis of indicators and critical scores.

plasmaprothrombin time, international normalized ratio, $\mathrm{D}$-dimer, and average hospital stay $(p<0.001-0.0001)$ (Table 2) and significantly decreased in PLT, $\mathrm{PaO}_{2} / \mathrm{FiO}_{2}$, urine volume, blood pressure, and fibrinogen $(p<0.01-0.0001)$ (Table 2). According to the analysis of the critical scores of each group, the critical scores of the latter 2 groups were significantly aggravated compared with the simple pneumonia group $(p<0.001)$. The regression analysis of the indicators and the critical scores found that the critical scores were related to the absolute value of $\mathrm{BE}$, Lac level, and the average length of hospital stay $(p<0.05)$ (Table 2). Compared with group II, the critical score of group III improved slightly $(p<0.05)$ (Table 2$)$, which was mainly reflected in the significantly decreased absolute value of $\mathrm{BE}, \mathrm{Lac}$, and average length of hospitalization days $(p<0.05-0.0001)$ (Table 2) and significantly increased values of PLT, $\mathrm{PaO}_{2} /$ $\mathrm{FiO}_{2}$, and urine volume $(p<0.05-0.001)$ (Table 2).

\section{Flow Cytometry and Initial ELISA Analysis}

According to the data of clinical and critical outcomes across groups, the number of leukocytes, especially mac- rophages, neutrophils, and T lymphocytes in peripheral blood and their functional activation and NET degeneration, were investigated. Compared with group I, the ratio of $\mathrm{CD} 63^{+} \mathrm{M} 1$ macrophages with normal activation function $(p<0.001)$ (Fig. 1; Table 3) and $\mathrm{CD}^{+} 3^{+}$neutrophil activation subpopulation $(p<0.0001)$ (Fig. 1; Table 3 ) and the number of $\mathrm{CD} 4^{+}$and $\mathrm{CD} 8^{+} \mathrm{T}$ cells, and the level of TNF- $\alpha$ also decreased ( $p<0.05-0.0001)$, while the level of elastase, CCR $2^{\text {high }} \mathrm{CX} 3 \mathrm{CR} 1^{\text {low }} / \mathrm{CCR} 2^{\text {low }} \mathrm{CX} 3 \mathrm{CR} 1^{\text {high }}$ of macrophages and neutrophils (Fig.1; Table 3), IL-10, and VEGF increased $(p<0.05-0.01)$ (Table 4$)$. It suggested that peripheral blood cells may endure immune depletion, paralysis, and incompetence and were in a refractory state, while NET-related molecules overactivation-induced vascular injury may be an important factor leading to the abovementioned criticality and biochemical indicators aggravated in group II with brain complications. Compared with group II, the ratio of $\mathrm{CD}^{+} 3^{+} \mathrm{M} 1$ macrophages $(p<0.05)$ (Fig. 1; Table 3$)$ and $\mathrm{CD}^{+} 3^{+}$neutrophil activation subpopulation $(p<0.05)$ (Fig. 1; Table 3 ) increased and the level of elastase and CCR2 ${ }^{\text {high }} \mathrm{CX}$ - 
$3 \mathrm{CR} 1^{\text {low }} / \mathrm{CCR} 2^{\text {low }} \mathrm{CX} 3 \mathrm{CR} 1^{\text {high }}$ of macrophages and neutrophils decreased $(p<0.05)$ (Fig. 1; Table 3$)$, while the number of $\mathrm{CD}^{+}$and $\mathrm{CD} 8^{+} \mathrm{T}$ lymphocytes and the level of TNF- $\alpha$, IL-10, and VEGF protein did not change significantly (Table 4). It suggested that group III without brain complication was related to the increasing number of $\mathrm{CD}^{+} 3^{+} \mathrm{M} 1$ macrophages and neutrophils with normal activation function, the improvement of the immune paralytic state of peripheral blood cells, and the reducing brain damage of CCR $2{ }^{\text {high }} \mathrm{CX} 3 \mathrm{CR} 1{ }^{\text {low }} \mathrm{M} 1$ macrophages and neutrophils and elastase.

\section{RT-PCR Analysis}

The mRNA expression levels of damage related molecules and their receptors were investigated by RT-PCR. The results showed that the mRNA expression levels of HMGB1 and RAGE in peripheral blood leukocytes in group II were significantly higher than those of group I $(p<0.001)$, while TLR9 was significantly decreased $(p<$ 0.0001 ) in group II (Fig. 2). The upregulated mRNA level of HMGB1 and RAGE and the immune paralysis state of TLR9 were consistent with the criticality and severity of biochemical indicators aforementioned in group II. The expression of mRNA HMGB1 and RAGE was decreased in group III than in group II $(p<0.05)$, while TLR9 was unchanged (Fig. 2).

For the expression of chemokines and inflammatory cytokines in peripheral blood leukocytes, the mRNA expression levels of CXCL9, CXCL10, TNF- $\alpha$, and IL-27 were significantly decreased in group II compared with group I ( $p<0.0001)$, while YTHDF1 and IL-17 were significantly increased $(p<0.01)$ (Fig. 2$)$. The apparent state of normal immune paralysis and abnormal immune overexpression was consistent with the most severe criticality of group II above. The mRNA expression of CXCL9 in group III increased to some extent compared with group II $(p<0.05)$, while the mRNA expression of CXCL10, TNF- $\alpha$, and IL-27 remained unchanged, and the mRNA expression of YTHDF1 and IL-17 significantly decreased $(p<0.05)$ (Fig. 2).

ELISA Analysis of Damage-Associated Molecule, Th1 Cells Chemokin, Th17 Cells Cytokin, Endothelial

\section{Factors, and S100B in Plasma}

Based on the results of immunological factor mRNA expression studies, the changes of plasma HMGB1, IL-17 (Th17 cell cytokine), and CXCL9 (Th1 cell chemokine) protein levels in each group were further studied. The results showed that HMGB1 and IL-17 proteins in group II increased significantly compared with group I $(p<0.001)$, and CXCL9 protein significantly decreased $(p<0.001)$. HMGB1 and IL-17 proteins in peripheral blood of group III decreased and CXCL9 protein increased to some extent $(p<0.05)$ (Fig. 3).

For plasma vascular endothelial injury and protective molecular protein expression in each group, the results showed that Ang2/Ang1 increased and sTIE2 decreased $(p<0.001)$ in group II compared with group I (Fig. 3). It suggested that the endothelial injury state was consistent with the most serious clinical outcome mentioned above in group II. The expression of sTIE2 protein increased in group III compared with group II ( $p<0.05)$, while Ang2/ Ang1 were unchanged (Fig. 3). For the brain injury index NSE, it was showed that the level of peripheral blood NSE protein in group II increased compared with group I ( $p<$ 0.001 ) (Fig. 3), while decreased in group III compared with group II $(p<0.05)$ (Fig. 3$)$.

\section{ELISpot Analysis of $C D 8^{+} C T L$ Function after LPS Stimulation}

The adaptive immune response of peripheral blood leukocytes in each group after LPS stimulation was investigated by ELISpot. The results showed that the number of cells forming IFN- $\gamma$ spot significantly decreased in group II compared with group I $(p<0.05)$ (Table 5). The status of $\mathrm{CD} 8^{+} \mathrm{CTL}$ immunological paralysis was consistent with the criticality and the severe biochemical parameters of group II (Table 2). The number of cells forming IFN- $\gamma$ spot in group III increased to some extent compared with group II $(p<0.05)$ (Table 5).

\section{Western Blot Analysis of HMGB1 and YTHDF1 in Peripheral Blood Leukocytes}

The results showed that HMGB1 and YTHDF1 proteins of peripheral blood leukocytes in group II increased significantly compared with group I ( $p<0.001-0.01)$, and HMGB1 and YTHDF1 proteins in peripheral blood leukocytes of group III decreased to some extent than group II $(p<0.05)$ (Fig. 4).

Fig. 1. Flow cytometry for peripheral blood CD63 + macrophages $\left(\mathrm{CD} 63+\mathrm{M} \varphi, \mathrm{CD} 3-\mathrm{CD} 11 \mathrm{~b}+\mathrm{ly} 6 \mathrm{~g}-\mathrm{CD}^{+} 3^{+}\right), \mathrm{CD} 63+$ neutrophils $\left(\mathrm{CD} 3-\mathrm{CD} 11 \mathrm{~b}+\mathrm{ly} 6 \mathrm{~g}+\mathrm{CD} 63^{+}\right), \mathrm{CCR} 2^{\text {high }} \mathrm{CX} 3 \mathrm{CR} 1^{\text {low }} / \mathrm{CCR} 2^{\text {low }} \mathrm{CX}-$ $3 \mathrm{CR} 1^{\text {high }}$ of macrophages ([CD $\left.11 \mathrm{~b}^{+} / \mathrm{ly} 6 \mathrm{~g}^{-} / \mathrm{CCR} 2^{\text {high }} \mathrm{CX} 3 \mathrm{CR} 1^{\text {low }}\right] /$ $\left.\left[\mathrm{CD} 11 \mathrm{~b}^{+} / \mathrm{ly} 6 \mathrm{~g}^{-} / \mathrm{CCR} 2^{\text {low }} \mathrm{CX} 3 \mathrm{CR} 1^{\text {high }}\right]\right)$, and CCR $2^{\text {high }} \mathrm{CX} 3 \mathrm{CR} 1^{\text {low }} /$ CCR $2^{\text {low }} \mathrm{CX} 3 \mathrm{CR} 1^{\text {high }}$ of neutrophils $\left(\left[\mathrm{CD} 11 \mathrm{~b}^{+} / \mathrm{ly} 6 \mathrm{~g}^{+} / \mathrm{CCR} 2^{\text {high- }}\right.\right.$ CX3CR $\left.\left.1^{\text {low }}\right] /\left[\mathrm{CD} 11 \mathrm{~b}^{+} / \mathrm{ly} 6 \mathrm{~g}^{+} / \mathrm{CCR} 2^{\text {low }} \mathrm{CX} 3 \mathrm{CR} 1^{\text {high }}\right]\right)$ and elastase ${ }^{+}$ neutrophils (elastase ${ }^{+} \mathrm{Neu}$ ). Note: Upper right quadrant indicates positive cell populations. Group I: mock group; group II: P2-24 group; group III: P2-48 group; group IV: P3-48 group. Data are shown as \% of positive cells in total white blood cells.

(For figure see next page.) 


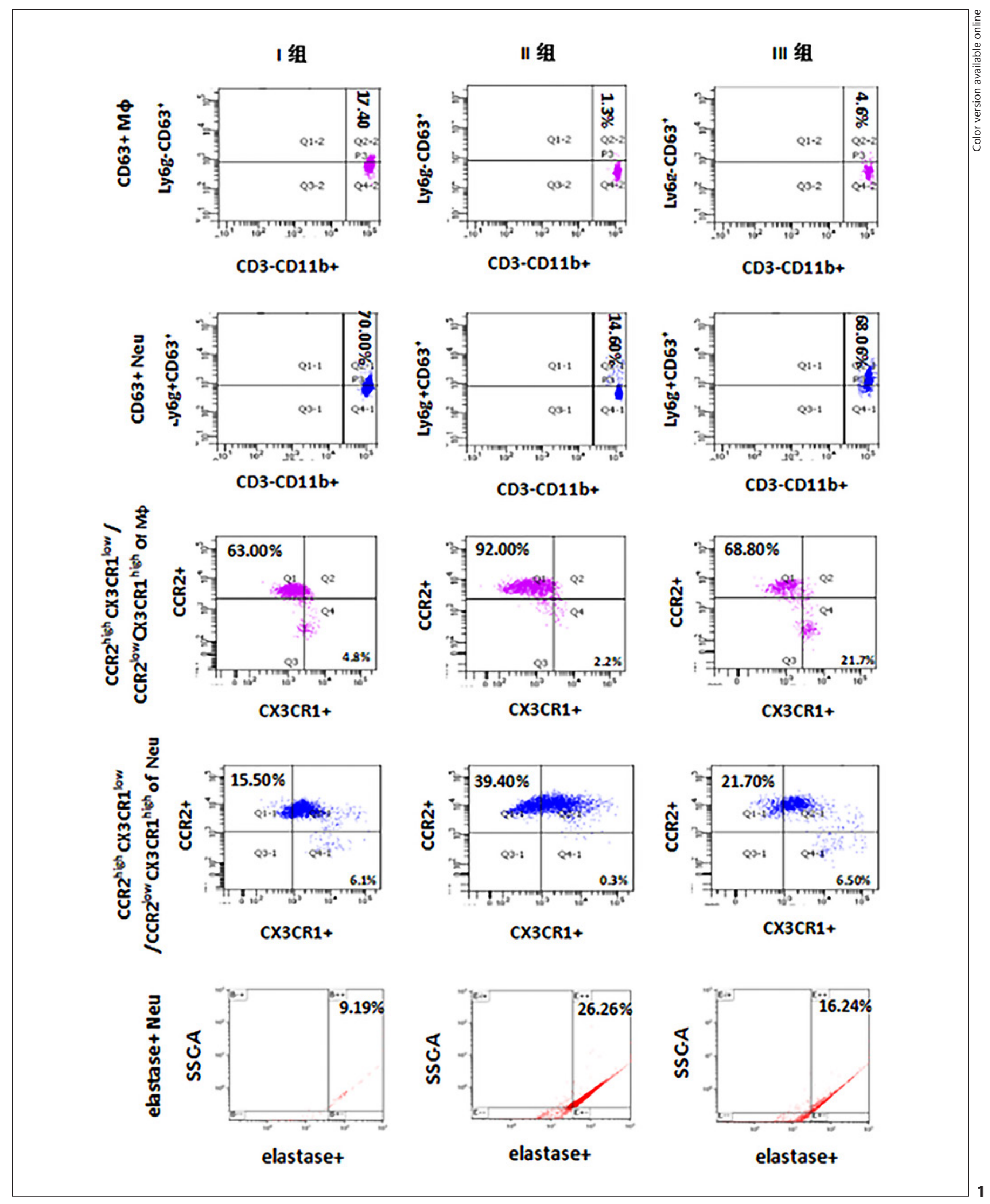

Immune Paralysis of Brain Injury with

Neuroimmunomodulation 2021;28:233-247 DOI: $10.1159 / 000509808$ 
Table 3. Data of peripheral blood macrophage and neutrophil cell subtype and the level of elastase by flow cytometry

\begin{tabular}{|c|c|c|c|c|c|}
\hline & \multicolumn{5}{|c|}{ Peripheral blood leukocytes } \\
\hline & \multicolumn{2}{|l|}{$\mathrm{CD} 11 \mathrm{~b} / \mathrm{CD} 63$} & \multicolumn{2}{|c|}{$\mathrm{CCR} 2^{\text {high }} \mathrm{CX} 3 \mathrm{CR} 1^{\text {low }} / \mathrm{CCR} 2^{\text {low }} \mathrm{CX} 3 \mathrm{CR} 1^{\text {high }}$} & \multirow[t]{2}{*}{ Elastase, \% } \\
\hline & $\mathrm{M} \varphi, \%$ & Neu, \% & $\mathrm{M} \varphi$ & Neu & \\
\hline Group I & $17.98 \pm 7.81$ & $70.99 \pm 17.27$ & $7.01 \pm 2.22$ & $2.94 \pm 0.53$ & $9.55 \pm 1.89$ \\
\hline Group II & $1.30 \pm 0.68^{* * *}$ & $14.15 \pm 4.47 * * * *$ & $45.31 \pm 8.46^{* * * *}$ & $60.13 \pm 11.01^{* * * *}$ & $25.38 \pm 3.82^{* * * *}$ \\
\hline$t$ value & 6.87 & 9.41 & 16.87 & 19.54 & 11.06 \\
\hline Group III & $4.60 \pm 1.51^{* *, \#}$ & $48.33 \pm 15.55^{* * *, \# \#}$ & $5.22 \pm 2.33^{* *}$,\#\#\# & 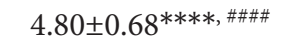 & $13.87 \pm 2.78^{* *, \#}$ \\
\hline$t$ value & $4.86,2.8$ & $8.56,4.23$ & $4.21,9.42$ & $11.23,9.21$ & $4.72,3.36$ \\
\hline
\end{tabular}

The proportion of cells in each group to the total CD11 b cells was as the unit of data in Table 3. Group I: simple pneumonia group; group II: pneumonia and severe sepsis with ECMO support with brain complication group; group III: pneumonia and severe sepsis with ECMO support without brain complication group. ECMO, extracorporeal membrane oxygenation. ${ }^{* *} p<0.01,{ }^{* * *} p<0.001,{ }^{* * * *} p<$ 0.0001 versus group I. ${ }^{\#} p<0.05,{ }^{\# \#} p<0.01,{ }^{\# \# \#} p<0.0001$ versus group II.

Table 4. Number of $\mathrm{CD} 4^{+}$and $\mathrm{CD} 8^{+} \mathrm{T}$ lymphocytes in peripheral blood detected by flow cytometry $(\mathrm{cell} / \mu \mathrm{L})$ and level of cytokine by ELISA (pg/mL)

\begin{tabular}{|c|c|c|c|c|c|}
\hline & \multicolumn{5}{|c|}{ Peripheral blood leukocytes } \\
\hline & \multicolumn{2}{|c|}{ T lymphocytes } & \multirow[t]{2}{*}{ TNF- $\alpha$} & \multirow[t]{2}{*}{ IL-10 } & \multirow[t]{2}{*}{ VEGF } \\
\hline & $\mathrm{CD}^{+}$ & $\mathrm{CD}^{+}$ & & & \\
\hline Group I & $571 \pm 42$ & $436 \pm 40$ & $8.13 \pm 1.07$ & $1.87 \pm 0.67$ & $85.46 \pm 45.23$ \\
\hline Group II & $316 \pm 45^{* * * *}$ & $355 \pm 53^{*}$ & $1.26 \pm 0.92^{* * * *}$ & $16.38 \pm 12.35^{*}$ & $492.35 \pm 201.91^{* *}$ \\
\hline$t$ value & 9.18 & 3.12 & 20.23 & 3.02 & 4.82 \\
\hline Group III & $443 \pm 72$ & $388 \pm 61$ & $1.75 \pm 0.49^{* * * *}$ & $18.87 \pm 14.31$ & $632.75 \pm 189.73^{* *}$ \\
\hline$t$ value & $2.46,2.21$ & $1.15,0.85$ & $15.11,0.66$ & $2.08,0.22$ & $5.01,0.89$ \\
\hline
\end{tabular}

Group I: simple pneumonia group; group II: pneumonia and severe sepsis with ECMO support with brain complication group; group III: pneumonia and severe sepsis with ECMO support without brain complication group. TNF- $\alpha$, tumor necrosis factor- $\alpha$; IL, interleukin; ECMO, extracorporeal membrane oxygenation; VEGF, vascular endothelial growth factor. ${ }^{*} p<0.05,{ }^{* *} p<0.01,{ }^{* * * *} p<0.0001$ versus group I.

\section{Discussion}

Clinically, some ECMO children with pneumonia and severe sepsis accompanied with brain complications. Serious cerebral infarction, hemorrhage, and brain abscess may occur, which may be difficult to be treated and may have poor prognosis. Preliminary studies have shown that the use of ECMO in pediatric patients can trigger the activation of pro-inflammatory cell signaling pathways, accompanied by adaptive immune cell mobilization and CNS-targeted adaptive immune response, which mainly occur in patients with acquired brain injury. These inflammatory mediators, including immune cells such as $T$ lymphocytes and B cells or cytokines such as IL-8, IL-6, IFN- $\gamma$, and IL-17, may be neurotoxic to the brain. How- ever, these studies mainly focused on changes in a few cytokines and a single subpopulation of cells. It suggests that innate and adaptive immune responses may be involved in the process [7]. However, various cell subpopulations and the upstream and downstream immune mechanisms are still unclear. Therefore, identification of the immune mechanism of ECMO children with pneumonia and severe sepsis accompanied by brain complications is essential, which will benefit the regulation of the innate and adaptive immune system and may have potential nervous protective effects on ECMO patients at risk of acquired brain injury.

So far, studies have found that immunosuppression is an important part of the pathophysiological mechanism of severe sepsis and is the main cause of late death in pa- 

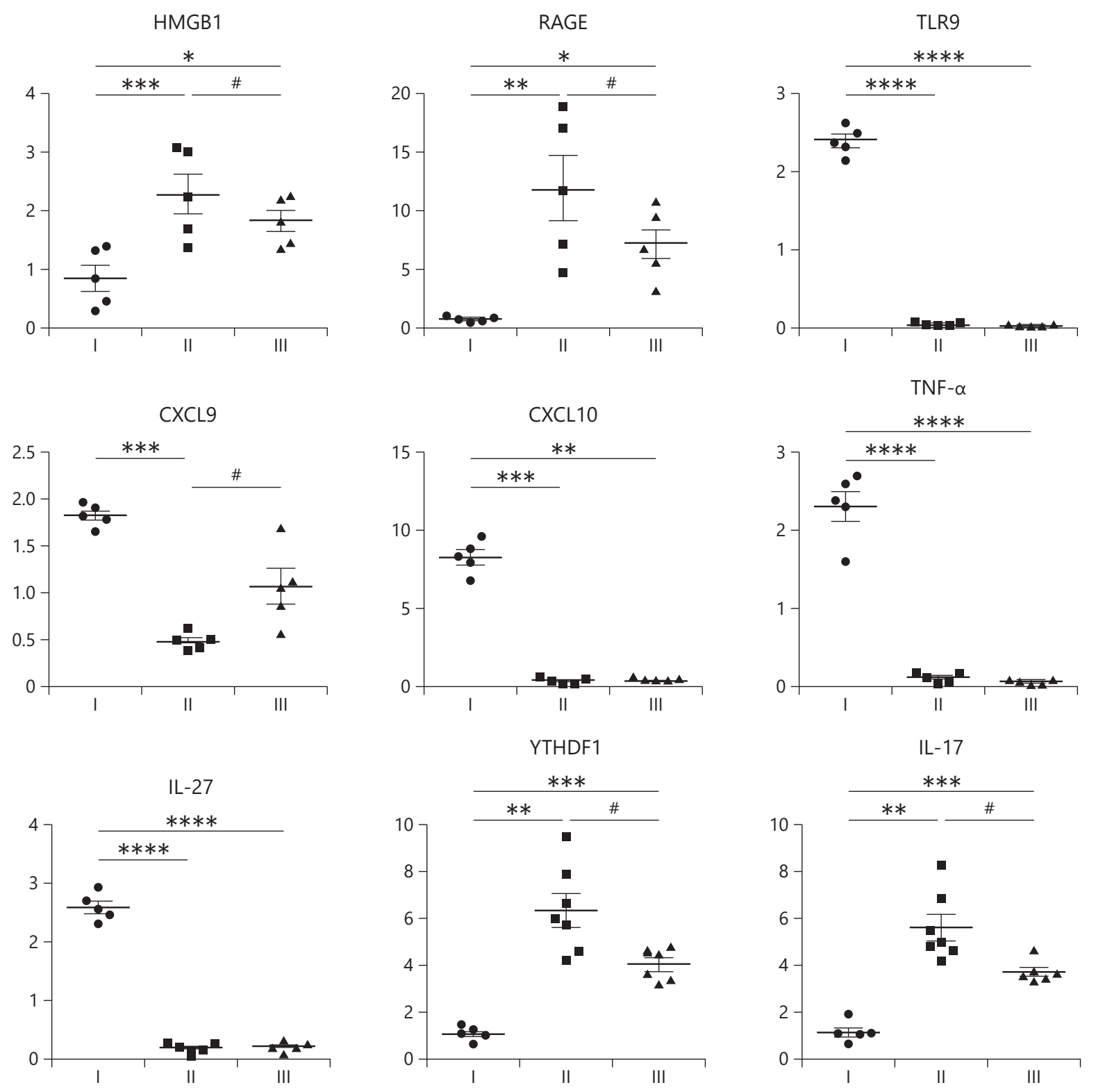

Fig. 2. Changes of mRNA level of molecules and receptors related to leukocyte injury in peripheral blood in 3 groups (relative CT values). Group I: simple pneumonia group; group II: pneumonia and severe sepsis with ECMO support with brain complication

tients with sepsis. Neutrophils can secrete a large number of cytokines, including immunosuppressive cytokine IL10 to inhibit T-lymphocyte proliferation in peripheral blood of endotoxemia patients. Research studies also shown that activation of signaling pathways associated with multiple inflammatory mediators promotes macro- group; group III: pneumonia and severe sepsis with ECMO support without brain complication group. ${ }^{*} p<0.05,{ }^{* *} p<0.01$, ${ }^{* * *} p<0.001,{ }^{* * * *} p<0.0001$ versus group I. ${ }^{*} p<0.05$ versus group II. ECMO, extracorporeal membrane oxygenation; IL, interleukin. phage apoptosis and inflammatory responses, such as the early cytokine TNF- $\alpha$ and HMGB1. It was confirmed that the activity of caspase-3 significantly increased in HMGB1-treated macrophage, leading to macrophage apoptosis. Functional changes in macrophages and increasing apoptosis will further exacerbate cellular im- 


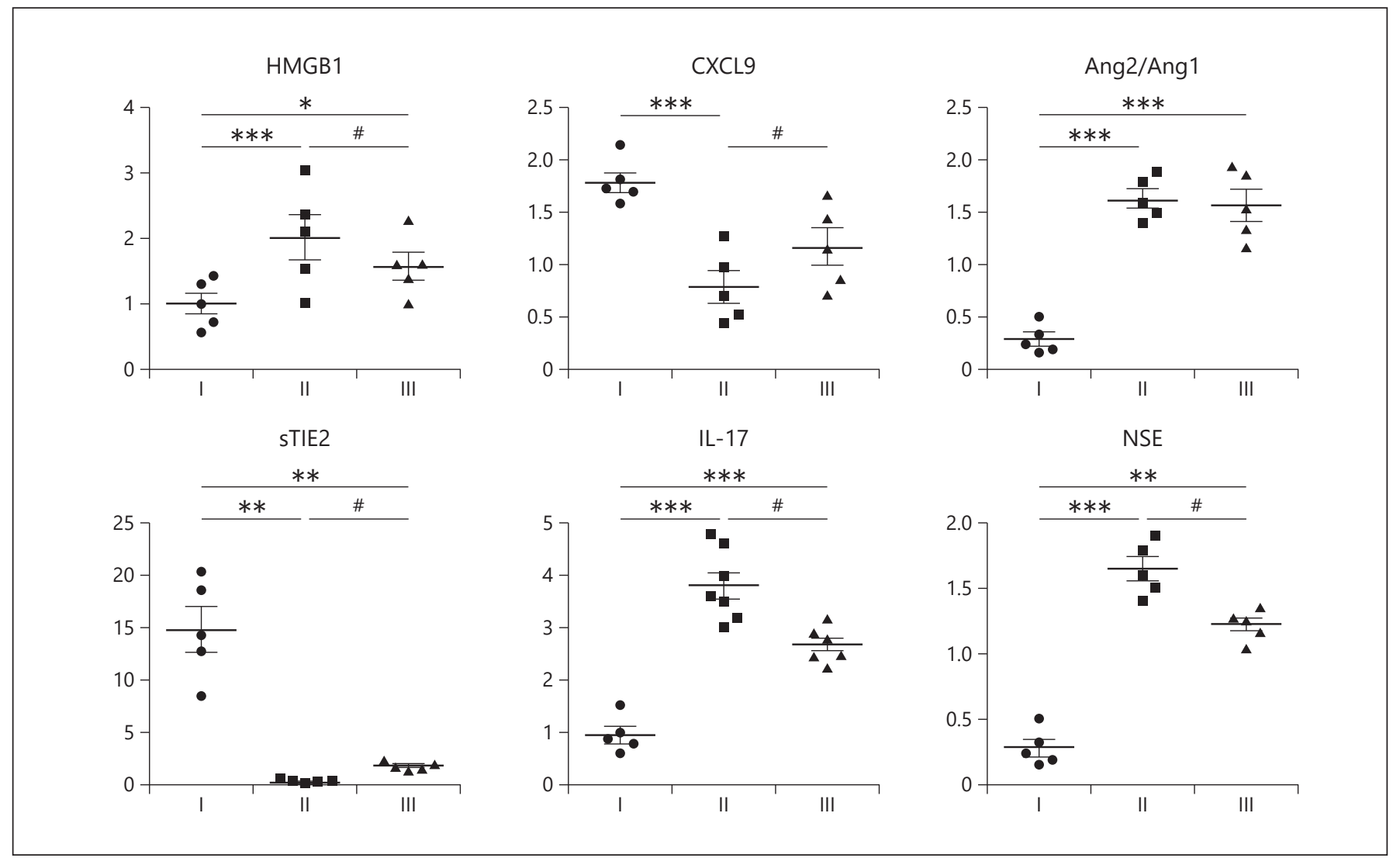

Fig. 3. Changes of plasma HMGB1, IL-17, CXCL9, vascular endothelial molecules, and NSE (pg/mL). Group I: simple pneumonia group; group II: pneumonia and severe sepsis with ECMO support with brain complication group; group III: pneumonia and severe

Table 5. Comparison of CD $8^{+} \mathrm{CTL}$ function after LPS stimulation in each group (spot-forming cells $2 \times 10^{5}$ cells)

Function of $\mathrm{CD} 8{ }^{+} \mathrm{CTL}$ after LPS stimulation

Group I

Group II

$157.10 \pm 25.34$

$t$ value

Group III

$27.53 \pm 19.72^{* * *}$

8.12

$44.27 \pm 13.40^{* * *, \#}$

$t$ value

$7.87,2.65$

Group I: simple pneumonia group; group II: pneumonia and severe sepsis with ECMO support with brain complication group; group III: pneumonia and severe sepsis with ECMO support without brain complication group. LPS, lipopolysaccharide; ECMO, extracorporeal membrane oxygenation. ${ }^{* * *} p<0.001$ versus group I. ${ }^{\#} p<0.05$ versus group II. sepsis with ECMO support without brain complication group. ${ }^{*} p<0.05,{ }^{* *} p<0.01,{ }^{* * *} p<0.001$ versus group I; ${ }^{*} p<0.05$ versus group II. HMGB1, high-mobility group box 1; IL, interleukin; ECMO, extracorporeal membrane oxygenation.

mune dysfunction during sepsis [13, 14]. Aren et al. [5] also found that immune cells were activated and secreted a large number of pro-inflammatory cytokines during the initial period of sepsis, subsequently, immune cell overapoptosis, leading to a decline in the number and function of immune cells, but regulatory immune cell subpopulation skewed, secreting inhibitory cytokines, resulting in a decrease in the number of $\mathrm{CD}^{+} \mathrm{T}$ lymphocytes and cellular immune function. All the above may be related to ECMO-related brain damage [7], while the whole inherent and adaptive immune mechanisms are still unclear.

$\mathrm{CD}_{11} \mathrm{~b}^{+}$is a surface molecular marker of the monocytes, including macrophages and neutrophils. The im-

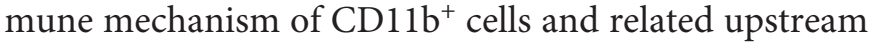
and downstream molecular responses in ECMO children with severe sepsis accompanied by lung to brain complications were investigated in the present research. It provided the treatment target and scientific research basis of 
Fig. 4. Protein expression of HMGB1and YTHDF1 in peripheral blood leukocytes detected via western blot. Group I: simple pneumonia group; group II: pneumonia and severe sepsis with ECMO support with brain complications group; group III: pneumonia and severe sepsis with ECMO support without brain complication group. ${ }^{* *} p<0.01,{ }^{* * *} p<0.001$ versus group I; ${ }^{\#} p<0.05$ versus group II. HMGB1, highmobility group box 1; ECMO, extracorporeal membrane oxygenation; GAPDH, glyceraldehyde-3-phosphate dehydrogenase.

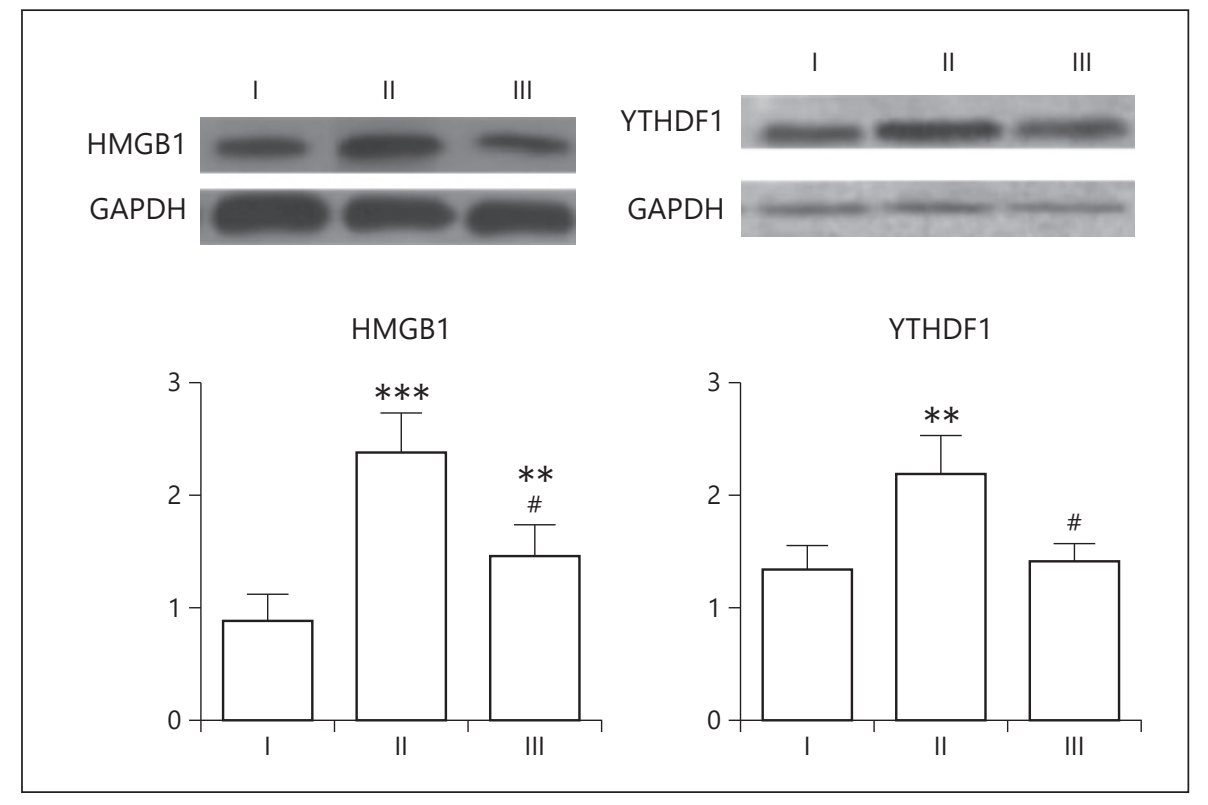

prognosis evaluation for early recognition and intervention in ECMO children with pneumonia and severe sepsis accompanied by brain complications, in order to reduce the mortality caused by brain complications, improve the survival rate, and improve their quality of life.

Firstly, regression analysis of various biochemical indicators and critical scores showed that the critical score was related to the absolute value of $\mathrm{BE}$, Lac in the 7th day of ECMO children, and the average length of hospital stay $(p<0.05)$. Compared with the simple pneumonia group, the absolute value of BE, Lac in the 7th day of ECMO children, and average hospitalization days were significantly increased in the ECMO children accompanied by brain complication group, while PLT, urine volume, and OI were significantly decreased $(p<0.001)$. Compared with the brain complication group, absolute BE value, Lac in the 7th day of ECMO children, and average hospitalization days in the ECMO children without the brain complication group decreased and PLT, urine volume, and OI increased $(p<0.05)$. It is of certain significance to confirm the clinical diagnosis to ECMO children with pneumonia and severe sepsis accompanied by brain complications. However, it was often in the middle and late stages if the above indicators change in the clinical stage. Therefore, these clinical indicators have limited significance to clinical diagnosis. It is necessary to further study the early warning and intervention immune biomarkers and its mechanism to achieve early individualized diagnostic assessment and active treatment and strengthen prevention.

Immune Paralysis of Brain Injury with Sepsis-ECMO
Therefore, the number and activation of immune cells playing an important role in the initial stage of sepsis such as neutrophils, macrophages, and Tlymphocytes were investigated in the present research. CD63 is an important degranulation marker of M1 macrophages and activated neutrophil, which may be closely related to the development of sepsis and inflammation $[15,16]$. Abnormal hyperimmunity in lung tissue after degranulation of CD1 $1 \mathrm{~b}^{+}$ macrophages and neutrophils, NET formation, and severe immune paralysis was related to more severe organ failure [17-20]. Therefore, different immune cell populations were defined according to different fluorescence refraction and cell sizes on flow cytometry. Combining with different cell sizes and fluorescence refraction,

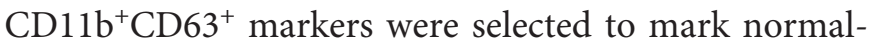
activated M1-type macrophages and neutrophils with normal degranulation function. Elastase was used to label NET-related molecules of denatured neutrophils forming. Since CCR $2{ }^{\text {high }} \mathrm{CX} 3 \mathrm{CR} 1{ }^{\text {low }}$ monocytes may be related to the inflammatory cells migrating into the brain which resulted in inflammatory reaction in the brain, CCR $2^{\text {high- }}$ CX3CR $1^{\text {low }}$ was chosen to stand for denatured monocytes inducing brain damage.

The results showed that in ECMO patients with pneumonia and severe sepsis accompanied by brain complication, the number of $\mathrm{CD}^{+} 3^{+} \mathrm{M} 1$ macrophages and neutrophil subpopulation in peripheral blood decreased and were in the immune paralysis state. Their $\mathrm{CD} 4^{+}$and $\mathrm{CD} 8^{+}$ T-cell number, and TNF- $\alpha$ level also decreased $(p<$ 0.001 ), and LPS-specific CD ${ }^{+} \mathrm{CTL}$ cytotoxicity was

Neuroimmunomodulation 2021;28:233-247 
weakened ( $p<0.001)$, while the level of elastase, CCR $2^{\text {high- }}$ CX3CR $1^{\text {low }} / \mathrm{CCR} 2^{\text {low }} \mathrm{CX} 3 \mathrm{CR} 1^{\text {high }}$ of macrophages and neutrophils, IL-10, and VEGF increased. It suggested that there was abnormal excessive inflammation in the lung tissue, which may further deplete the normal immune cells released by the bone marrow, resulting in the lose of normal immunity compensatory ability in the bone marrow completely. The body was in a refractory period in which the immune system was severely depleted and paralyzed, resulting in immunologically paralysis of $\mathrm{CD} 63^{+}$ M1 macrophage and neutrophil subpopulations released from the bone marrow to the peripheral blood.

Abnormal over-immunization of the lung tissue, such as degranulation after monocyte activation, NET formation, imbalance of Th1/Th2 ratio after activation of monocytes, and imbalance of Treg leading to the rise of the IL-10 level [17-20], further lead to the abovementioned severe immune paralysis of the peripheral blood and severe organ failure. The increase in the VEGF level may indicate pulmonary vascular injury. It is reported that a large amount of cell infiltration and exudation filled in the alveolar cavity, and a large area of alveolar consolidation and thickening of the alveolar interstitial layer and the emphysema appearing instead of normal alveolar structures in pathology suggested that severe vascular leakage leads to severe pathological changes in the lungs during severe sepsis [21], which is consistent with the more serious absolute value of BE, Lac content, the longer average length of hospital stay, and higher criticality found in our present research.

The significantly increasing mRNA expression levels of HMGB1, RAGE, YTHDF1, and IL-17 ( $p<0.001-0.01)$; the decreasing mRNA expression levels of TLR9, CXCL9, CXCL10, TNF- $\alpha$, and IL-27 ( $p<0.0001-0.001)$ in peripheral blood leukocytes; the increasing expression level of HMGB1, YTHDF1, IL-17, and Ang2/Ang1 protein; and the decreasing level of CXCL9, sTIE2 protein in plasma, or peripheral blood leukocytes $(p<0.0001-0.01)$ suggested that the peripheral blood leukocyte HMGB1 and its receptor RAGE overregulated persistently, and the YTHDF1 level also upregulated and caused this severe immune paralysis condition even with brain complications. It was reported that YTHDF1 promotes JAK2/ STAT3 methylation signal and protein translation, while JAK2/STAT3 can promote IL-17 expression, leading to excessive immunization and subsequent immune paralysis $[22,23]$ and further consumption of neutrophils and macrophages, presenting a persistent immunological paralysis status with a significant decrease in TLR9, CXCL9, CXCL10, TNF- $\alpha$, and IL-27 expression. It may result in a decrease in the number of $\mathrm{CD}^{+}$and $\mathrm{CD}^{+} \mathrm{T}$ lymphocytes and the weakening LPS-specific $\mathrm{CD} 8^{+}$CTL cytotoxic killing function in the peripheral blood and presented an immunological paralysis status. While the increasing level of IL-17 may be related to the upregulation of CCR $2^{\text {high }} \mathrm{CX} 3 \mathrm{CR} 1^{\text {low }} / \mathrm{CCR} 2^{\text {low }} \mathrm{CX} 3 \mathrm{CR} 1^{\text {high }}$ of monocytes migrating into the brain, which resulted in the inflammatory reaction in the brain [7, 24], HMGB1/RAGE/ YTHDF1 may play a role through the upregulation of IL17 and CCR $2^{\text {high }} \mathrm{CX} 3 \mathrm{CR} 1^{\text {low}} / \mathrm{CCR} 2^{\text {low }} \mathrm{CX} 3 \mathrm{CR} 1^{\text {high }}$ of monocytes, which was consistent with the brain complications resulted from ECMO-surported pneumonia accompanied by severe sepsis, more severer absolute $\mathrm{BE}$ value, Lac content, and the longer average length of hospital stay.

The significantly increased mRNA level of HMGB1 and its receptor RAGE, as the damage-related molecule at the most upstream of peripheral blood leukocyte gene expression in group II $(p<0.05)$, is the main early marker of worsened severe sepsis. It has been reported that HMGB1/RAGE may induce lung necrosis by recruiting neutrophils and generating elastase [25]. In addition, HMGB1 can upregulate NF- $\kappa B$ in endotoxin-stimulated macrophages, stimulate TNF- $\alpha$ secretion, and further activate and consume neutrophils and macrophages in pneumonia and severe sepsis patients, resulting in aggravated damage in lungs with sepsis [26]. In patients with septic shock and animal models, the HMGB1 level showed a continuous rise in the late stage of sepsis, which can lead to the inactivation of neutrophil NADPH oxidase and reduce its antibacterial ability, which was related to the mechanism of lethal immune paralysis in severe septic shock [27]. HMGB1 may drive the expansion of $\mathrm{CD} 11 \mathrm{~b}^{+} \mathrm{Gr}-1^{+}$myeloid-derived suppressor cells (MDSCs) through binding with these mediators in a lymphoid compartment after trauma, while treatment with antiHMGB1 antibody ameliorated the expansion of $\mathrm{CD} 11 \mathrm{~b}^{+} \mathrm{Gr}-1^{+} \mathrm{MDSC}$ and the accumulation in the spleen in the late posttraumatic term, which also decreased the $\mathrm{CD} 11 \mathrm{~b}^{+} \mathrm{Gr}-1^{+} \mathrm{MDSC}$ mediation of $\mathrm{T}$-cell suppression [28]. It is consistent with the upregulation of HMGB1 and its receptor RAGE in the brain complication group caused by ECMO-surported pneumonia with severe sepsis and the increase elastase + denatured neutrophils but the reduction of peripheral blood-activated normal CD3CD11b + Ly6g + CD63 + neutrophils and CD3-CD11b + Ly6g-CD63 + macrophages $(p<0.0001-0.01)$ and the serious clinical outcomes in our studies. The bone marrow in this group with brain complication overexhausted $\mathrm{CD} 11 \mathrm{~b}^{+} \mathrm{Gr}-1^{+} \mathrm{MDSC}$ at an early stage and completely 
lost the ability to late-stage compensate for a pathologyrelated loss of normal immune cells in the host, which resulted in the peripheral blood immune paralytic conditons in our study.

It had been reported that IL-27 can resist bacterial growth and mediate mouse bone marrow suppressor cells against macrophage over-inflammation [29]. It is of note that HMGB1 is one of several known ligands for TLR4 and TLR9 receptors. It was identified that TLR9 contributed only to immunosuppressed T-lymphocyte responses after peripheral tissue injury [28]. Our findings suggest that IL-27 and TLR9 exhausted after hyperinflammatory response which may be related to lethal immune paralysis of neutrophils and macrophages caused by increased HMGB1/RAGE/YTHDF1 and further depletion of peripheral blood CD63 + neutrophils and CD63 + macrophages as mentioned above and cause a kind of immunoanergy of cytoxic $\mathrm{T}$ lymphocytes in the group with brain complications, while the group without brain complications did not change anything about IL-27 and TLR9 exhaustion. It suggested that HMGB1 may use some other alternate mechanisms following this kind of fatal injury that leads to immunoparalysis. Compared between the group with brain complications and that without, HMGB1/RAGE/YTHDF1 induced the above intrinsic $\mathrm{CD} 11 \mathrm{~b}+$ cellular and all kinds of immunological paralysis, which may be caused by the decreased mRNA and protein expression levels of Th1-skewed chemokin CXCL9 $(p<0.001-0.05)$ and increased mRNA and protein expression levels of Th17 cytokine IL-17 $(p<0.001-$ $0.01)$, resulting in the peripheral blood showing an adaptive immune paralysis state, such as a decrease in CD4+CD8+ T lymphocytes $(p<0.001-0.05)$ and weakened LPS-specific CD8+CTL cytotoxic killing function ( $p$ $<0.001$ ), which were consistent with clinical outcomes in children associated with brain complications.

Studies on downstream endothelial effector cells revealed that the intrinsic and adaptive immune paralytic states mentioned above, accompanied by mechanisms of endothelial injury with an increased Ang2/Ang1 level and a decreased sTIE2 $(p<0.05)$, were consistent with severe clinical outcomes in the brain. It had been reported that the imbalance of TIE2/Ang2 in severe pulmonary infections was associated with pulmonary vascular leakage [30]. LPS improved the Ang-2 expression level and inhibited Ang-1 and Tie-2 expressions, which was associated with endothelial injury [31] and caused the downregulation of tight junction protein OCCLUDIN. Low-dose LPS upregulated the VE-CAD level and high-dose LPS downregulated VE-CAD expression [32], which was consistent with endothelial injury in our study results, such as the rise of the Ang2/Ang1 level and the decreased sTIE2 level in blood. The occurrence of the capillary leakage mechanism caused by tight junction protein damage was consistent with the clinical critical outcome of brain complications.

Our results also showed that children without brain complications had slightly better clinical outcome, and the absolute value of $\mathrm{BE}$, Lac content, and average hospital stay were significantly lower, and PLT, $\mathrm{PaO} 2 / \mathrm{FiO} 2$, and urinary output were significantly increased. These clinical indicators were consistent with inhibition of abnormal over-immunity of HMGB1, YTHDF1, and IL-17 proteins in peripheral blood; improvement of the immune paralysis state of CD63 $+\mathrm{CD} 11 \mathrm{~b}+\mathrm{M} 1$ macrophage and neutrophil subgroups in peripheral blood; the downregulated elastase + denatured neutrophils andCCR2highCX3CR1low/CCR2lowCX3CR1high of monocytes; the upregulated Th1 cell chemokine CXCL9 protein expression and LPS-specific CD8+CTL cytotoxicity, and the upregulated expression of endothelial protective protein sTIE2, which could improve normal immunity and protect endothelial cell integrity and inhibit inflammatory cells into brain.

\section{Conclusion and Prospect}

Pneumonia accompanied by severe sepsis with ECMO support and subsequent brain complications is associated with the paralysis of the $\mathrm{CD}^{+} 3^{+}$degranulation activity of

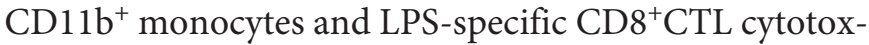
ic killing function, in which upstream molecules such as HMGB1/RAGE and YTHDF1 in CD11 $\mathrm{b}^{+}$cells overexpressed, resulting in downregulation of $\mathrm{CD} 11 \mathrm{~b}^{+}$cell-secreted CXCL9 chemokines recruiting Th1 cells mainly and promoting the upregulation of IL-17 factors, making the imbalance of Th17/Th1. This makes inflammation entering the brain by increasing elastase and the ratio of CCR $2{ }^{\text {high }} \mathrm{CX} 3 \mathrm{CR} 1^{\text {low }} / \mathrm{CCR} 22^{\text {low }} \mathrm{CX} 3 \mathrm{CR} 1^{\text {high }}$ of monocytes, aggravating endothelial damage, destroying the integrity of the blood-brain barrier and further aggravating brain inflammation. Our research provides a scientific basis for identifying early warning indicators of brain complications subsequent to ECMO-surported children with pneumonia accompanied by severe sepsis. The impact on the prognosis of large clinical samples will be a research direction. 


\section{Acknowledgement}

The authors wish to thank the Peking Army General Hospital for early guidance of the ECMO systems used here.

\section{Statement of Ethics}

This study has passed the review of ethics committee of Zhengzhou University (Ethical reference number: 2019-01-006) and the Informed consent was signed.

\section{Conflict of Interest Statement}

All authors have no competing interests, agreed to the consent for publication.

\section{Funding Sources}

This work was supported by 2019 Service improvement project of provincial medical institutions.

\section{Author Contributions}

Yan Xing was responsible for the study design, analyzing and interpreting the data, writng the manuscript. DongLiang Cheng collected samples and data, performed clinical indexes and some molecular experiments, assisted to interpretation, help to draft the manuscript. ChangSong Shi and Zhiqiang Shen supported the study conduct, discussed the data, and participated in data interpretation and manuscript preparation. All authors read and approved the final manuscript.

\section{References}

1 Igor R, Cynthia BP, Zrinka B, Mulholland K, Campbell H. Epidemiology and etiology of childhood pneumonia. Bull World Health Organ. 2008;86(5):408-16.

2 Scott JA, Brooks WA, Peiris JS, Holtzman D, Mulholland EK. Pneumonia research to reduce childhood mortality in the developing world. J Clin Invest. 2008;118(4):1291300.

3 Fleischmann-Struzek C, Goldfarb DM, Schlattmann P, Schlapbach LJ, Reinhart K, Kissoon N. The global burden of paediatric and neonatal sepsis: a systematic review. Lancet Respir Med. 2018;6(3):223-30.

4 Yan G, Lu G. Application of extracorporeal membrane oxygenation in children with septic shock. Chinese Pediatr Emerg Med. 2018; 25(7):503-6.

5 Arens C, Bajwa SA, Koch C, Siegler BH, Schneck E, Hecker A, et al. Sepsis-induced longterm immune paralysis-results of a descriptive, explorative study. Crit Care. 2016;20(2): 93-104.

6 Bermejo-Martin JF, Andaluz-Ojeda D, Almansa R, Gandía F, Gómez-Herreras JI, Gomez-Sanchez E, et al. Defining immunological dysfunction in sepsis: a requisite tool for precision medicine. J Infect. 2016;72(5):52536.

7 Sterling BO, Poornima P, Jana W, Vanessa OT, Uma MS, Amy L, et al. A pilot study identifying brain-targeting adaptive immunity in pediatric extracorporeal membrane oxygenation patients with acquired brain injury. Crit Care Med. 2019;47(3):e206-e213.

8 Mandell LA, Wunderink RG, Anzueto A, Bartlett JG, Campbell GD, Dean NC, et al. Infectious diseases society of America/American thoracic society consensus guidelines on the management of community-acquired pneumonia in adults. Clin Infect Dis. 2007; 44(Suppl 2):S27-72.
9 Singer M, Deutschman CS, Seymour CW, Shankar-Hari M, Annane D, Bauer M, et al. The third international consensus definitions for sepsis and septic shock (sepsis-3). JAMA. 2016;315(8):801-10.

10 Zhuang W, Lin G, Zheng H, Chen PZ, Lin CX, Zhou RB. Clinical diagnosis and treatment of sepsis associated encephalopathy in children. ChinesePediatr Emerg Med. 2007;14(4):3841.

11 Song G. Pediatric critical illness score. Chinese J Emerg Med. 2003;12(5):359-60.

12 Xing Y, Song HM, Wei M, Liu Y, Zhang YH, Gao L. Clinical significance of variations in levels of epstein-barr virus (EBV) antigen and adaptive immune response in chronic active EBV infection in children. J Immunotoxicology. 2013;10(4):387-92.

$13 \mathrm{He}$ X, Bo L, Jiang C. Research progress of immunosuppression and immunostimulation therapy in sepsis. Chinese Emerg Med Crit Ill. 2018;30(12):1202-5.

14 Xu X, Wang M. Immunosuppression of sepsis. Int J Pediatr. 2018;45(11):817-21.

15 Nigorikawa K, Hazeki K, Guo Y, Hazeki O. Involvement of class II phosphoinositide 3-kinase $a$-isoform in antigen-induced degranulation in RBL-2H3 cells. PLoS One. 2014;9(10):e111698.

16 Droemann D, Hansen F, Aries SP, Braun J, Zabel P, Dalhoff K, et al. Neutrophil apoptosis, activation and anti-inflammatory cytokine response in granulocyte colony-stimulating factor-treated patients with community-acquired pneumonia. Respiration. 2006; 73(3):340-6.

17 Ishikawa M, Yamashita H, Oka N, Ueda T, Kohama K, Nakao A, et al. Antithrombin III improved neutrophil extracellular traps in lung after the onset of endotoxemia. Scand J Immunol. 2016;84(6):33843.
18 Hawley KL, Cruz AR, Benjamin SJ, La Vake CJ, Cervantes JL, LeDoyt M, et al. IFN $\gamma$ Enhances CD64-Potentiated Phagocytosis of. Front Immunol. 2017 Oct 5;8: 1227.

19 Soria I, López-Relaño J, Viñuela M, Tudela JI, Angelina A, Benito-Villalvilla C, et al. Oral myeloid cells uptake allergoids coupled to mannan driving Th1/Treg responses upon sublingual delivery in mice. Allergy. 2018; 73(4):875-84.

20 Leliefeld PHC, Wessels CM, Leenen LPH, Leo $\mathrm{K}$, Pillay J. The role of neutrophils in immune dysfunction during severe inflammation. Criti Care. 2016;20:73.

21 Sakamoto N, Tsuchiya K, Hikone M. Community-acquired necrotizing pneumonia with bacteremia caused by Pseudomonas aeruginosa in a patient with emphysema: an autopsy case report. Respir Investig. 2018;56(2): 189-94.

22 Ruifan W, Youhua L, Yuanling Z, Zhen B, Yongxi Y, Qing L, et al. m6A methylation controls pluripotency of porcine induced pluripotent stem cells by targeting SOCS3/JAK2/ STAT3 pathway in a YTHDF1/YTHDF2-orchestrated manner. Cell Death Dis. 2019;10: 171-86.

23 Marianne B, Marine G, Sebastian A. Translate less, prime better, to improve anti-tumor responses. Nature Immunology. 2019;20(5): $518-26$.

24 Xiang F, Zhang Q, Yao Y. Research progress on immune dysfunction mechanism of septic encephalopathy. Chin J Burn. 2011;27(2): $128-30$.

25 Huebener P, Pradere J-P, Hernandez C, Gwak GY, Caviglia JM, $\mathrm{Mu} \mathrm{X}$, et al. The HMGB1/RAGE axis triggers neutrophil-mediated injury amplification following necrosis. J Clin Invest. 2019;130(4): 1802-10. 
26 Gil M, Kim YK, Hong SB, Lee KJ. Naringin decreases TNF-aand HMGB1 release from LPS-stimulated macrophages and improves survival in a CLP-induced sepsis mice. PLoS ONE. 2016;11(10): 0164186.

27 Grégoire M, Tadié JM, Uhel F, Gacouin A, Piau C, Bone N, et al. Frontline science: HMGB1 induces neutrophil dysfunction in experimental sepsis and in patients who survive septic shock. J Leukoc Biol. 2017;101(6): 1281-7.
28 Ruan X, Darwiche SS, Cai C, Scott MJ, Pape HC, Billiar TR. Anti-HMGB1 monoclonal antibody ameliorates immunosuppression after peripheral tissue trauma: attenuated $\mathrm{T}$ lymphocyte response and increased splenic CD11b (+) Gr-1 (+) myeloid-derived suppressor cells require HMGB1. Mediators Inflamm. 2015:458626.

29 Gleave Parson M, Grimmett J, Vance JK, Witt MR, Seman BG, Rawson TW, et al. Murine myeloid-derived suppressor cells are a source of elevated levels of interleukin-27 in early life and compromise control of bacterial infection. Immunol Cell Biol. 2018 Dec 21.
30 Kümpers P, Alexander L. The curse of angiopoietin-2 in ARDS: on stranger TI (E) des. Crit Care. 2018;22(1):44

31 Zeng H, He X, Tuo Q, Liao DF, Zhang GQ, Chen JX. LPS causes pericyte loss and microvascular dysfunction via disruption of Sirt3/ angiopoietins/ Tie-2 and HIF-2 $\alpha /$ Notch3 pathways. Sci Rep. 2016.

32 Zheng X, Wang Z, Hu X. Different concentrations of lipopolysaccharide regulate barrier function through the PI3K/Akt signalling pathway in human pulmonary microvascular endothelial cells. Sci Rep. 2018(8):9963. 